\title{
DE VERBORUM DEPONENTIUM USU PASSIVO IN COMOEDIS PLAUTINIS ADNOTATIONES QUAEDAM ${ }^{1}$
}

Nonnullis formis verborum deponentium Romanos et voce passiva uti satis constat. Quarum de origine et ratione grammatici certant et adhuc sub iudice lis est: sunt, ${ }^{2}$ qui formas passivas e formis activis (quae etsi nusquam reperiuntur, tamen restitui possunt) fieri, quorum iudicio alii viri docti $^{3}$ resistant, qui istas verborum deponentium formas passivas esse contendunt.

Plurima exempla vocis passivae in formis periphrasticis, praecipue e copula et participio perfecti compositis, inveniuntur. In formis non periphrasticis thematis praesentis apud Plautum unum tantum exemplum vere passivae notionis repperimus:

\section{Ep. 267: continuo arbitretur uxor tuo gnato /.../}

Si aliud quoddam exemplum non periphrasticum invenitur, certe forma passivum, notione impersonale putandum est; quae ad exempla adnotatiunculae nostrae pertinent.

Einarus Löfstedt in Syntacticis ${ }^{4}$ huiusmodi verborum constructiones formas ad notionem accomodatas (Angleichung der Form an die Bedeutung) nominat quaeritque, qua de causa id saepissime in modo infinitivo, rarius alibi in usum veniat. $R e-$ spondet formas personales paradigmate velut in acie se tutari, infinitivum sine ope eorum stantem impetui notioonis propriae resistere non posse formaque passiva vinciri.

Petrus Flobert in mirabili suo libro De linguae Latinae verbis deponentibus omnia fere exempla impersonalia collegit (sola Most. 960 et Am. fr. XII eum effugisse videntur); quas si legiones in manipulos cohortesque divisisset, dubium non est, quin omnem sibi laudem habiturus fuerit.

1 Gratias ago maximas professori Gantar, viro docto, qui hoc opusculum non indignum inspectu putaverit.

Ad ipsius Plauti verba ponenda usus sum editione Friderici Ritschl, Lipsiae MDCCCLXXXVII MDCCCXCIV.

2 Prisciani Institutiones; Keil, Grammatici Latini, II, 425, Lipsize 1885; Gonzalez Lodge, Lexicon Plautinum, Lipsiae MCMXXIV

3 Pierre Flobert, Les verbes déponents latins des origines à Charlemagne, Paris 1975; R. Kühner - C. Stegmann, Ausführliche Grammatik der lateinischen Sprache, Hannover 1912 (ed. secunda), p. 111

4 Einar Löfstedt, Syntactica, Studien und Beiträge zur historischen Syntax des Lateins, Lund 1933, II, pp. $124 \mathrm{~s}$ 
Verba deponentia voce passiva apud Plautum in huius generis sententiis usurpantur:

1. Sententiae proverbiorum instar, in quibus agens ne e contextu quidem orationis conici potest; quamquam Plautus in huiusmodi sententiis formas deponentium impersonales quovis modo evitat, potest et aliter dicere, potest 2. persona singularis activi uti (ut quidem nostra, id est Slovenica, lingua):

Truc. 662: Nullam rem oportet dolose adgrediri, nisi astute adcurateque exsequare.

Verbis deponentibus hoc modo in comoediis suis bis tantum usus est:

Trin. 367: Non aetate, verum ingenio apiscitur sapientia.

Am. 651: libertas salus, vita, res et parentes, patria et prognati tutantur, servantur.

2. Verbis, quae natura minus commode sonant, forma impersonali incrementum affertur; qua oratione Romanus agentem quasi nihili putans, etsi novit, praeterit: Most. 959 ss: Triduom unumst haud intermissum hic esse et bibi, scorta duci, pergraecari, fidicinas tibicinas conducti. (sc. Philolaches cum amicis pergraecantur) Ps. 687: sed iam satis est philosophatum. (sc. satis philosophatus sum)

Poen. $524 \mathrm{~s}$ : praesertim in re populi placida atque interfectis hostibus non decet tumultuari.

3. Personae in comoediis ad imperandum non solum imperativo modo, sed etiam circumlocutionibus utuntur; quibus in circumlocutionibus indicativum volo/iubeo infinitivus praesentis passivi sequitur.

Huiusmodi sententiis praecipue domini servis nobilesque minus nobilibus mandata dant. Modus infinitivus in huiusmodi circumlocutione cum nulla forma alternari potest, praesertim cum Plautus hoc modo et verba activa saepissime usurpet. Itaque activis his verbis utitur:

Cas. 170: iussin colum ferri mihi?

Most. 181: Ego verum amo, verum volo dici mihi.

itidem et deponentibus:

Most. 371: iube haec hinc omnia amolirier.

Am. fr. XII: quaeso advenienti morbo medicari iube.

4. Ubi, qui loquitur, opus ipse perfecturus est, saepe urbana quadam forma futuri temporis utitur: dabitur pro dabo dicit, videbitur pro videbo. Eodem modo pro nil moror invenimus:

Men. 326: nihil morabitur.

Mil. 1305: non morabitur.

Formae impersonales verborum deponentium apud Plautum raro in usum veniunt (nam supra paene omnes enumerantur) idque eodem genere sententiarum, quo et verba activa interdum impersonaliter usurpantur.

Vicinitas verborum formam impersonalem exigens nec verbis deponentibus ignoscere videtur, videlicet modo infinitivo et tertia persona singularis vel pluralis. 
Itaque doctissimi Löfstedt opinio infinitivum proniorem in mutandam vocem esse et ad formas tertiae personae valet.

Hac notione deponentia rariora tantum apud Plautum reperiuntur, nusquam illa, quae deponentia esse nemo ignorat, velut loquor, utor, sequor eorumque composita (cf. supra Truc. 662).

Povzetek

\section{NEKAJ OPOMB O PASIVNI RABI DEPONENTNIKOV PRI PLAVTU} tipih:

Pri nesestavljivih oblikah gre večinoma za brezosebno pasivno rabo. Najdemo jo le v 4 stavčnih

a) pregovori in splošne resnice,

b) izpovedi in prepovedi po obrazcu volo/iubeo + inf. prez. pas.,

c) izjave tipa dabitur: brezosebni pasiv najdemo pri nedoločniku in oblikah za 3.os.edn. in mn., a le pri manj pogostih deponentnikih,

c) pasiv pri glagolih s slabšalnim pomenom. 